\title{
Physical and Mechanical Properties of Particleboard Manufactured from Wood, Bamboo and Rice Husk
}

\author{
Rafael Rodolfo de Melo*, Diego Martins Stangerlin, \\ Ricardo Robinson Campomanes Santana, Talita Dantas Pedrosa \\ Instituto de Ciências Agrárias e Ambientais, Universidade Federal de Mato Grosso - UFMT, \\ CEP 78557-267, Sinop, MT, Brazil
}

Received: August 16, 2013; Revised: March 19, 2014

\begin{abstract}
In this work, the physical-mechanical properties of particleboards manufactured with wood (Eucalyptus grandis), bamboo (Bambusa vulgaris) and/or rice husk (Oryza sativa) particles, combined or not, were assessed. They were produced in the following proportions: $100 \%$ wood; $100 \%$ bamboo; $100 \%$ rice; $50 \%$ wood and 50\% bamboo; 50\% wood and 50\% rice husk. In order to characterize the manufactured particleboards, their physical (density; moisture content; water absorption and thickness swelling) and mechanical properties (static bending; internal bonding and screw withdrawal) were assessed. The results indicated that the use of rice husk caused reduction in particleboard quality. Particleboards manufactured with bamboo showed better quality than those using rice husk as raw material. For most parameters, the particleboards manufactured exclusively with wood particles showed similar performance to bamboo and wood-bamboo particleboards.
\end{abstract}

Keywords: panels, rice husk, Bambusa vulgaris, physical-mechanical properties

\section{Introduction}

Owing to the rise in wood consumption, the reserves of native woody species have been decreasing, causing the search for new renewable lignocellulosic materials that may efficiently meet the demand. This environmental pressure supports research regarding new products and a better utilization of the raw material available. Residue reutilization has been increasing, thus several researches have been investigating the characteristics of particleboards produced with these residues. Furthermore, there is the possibility of combining wood with other lignocellulosic materials aiming at obtaining more profitable products and with environmental marketing strategies, without reducing its quality.

The particleboard industry in Brazil uses mostly wood shavings from reforested, resulting in a higher quality product due to better control of the homogeneity of raw material. However, in view of Brazil's agricultural boom and the resulting increase in agricultural wastes, a recent alternative for particleboard production may be the use of agroindustrial lignocellulosic wastes to replace solid wood particles in the manufacture of composite panels ${ }^{1}$.

At first, any lignocellulosic material can be used as raw material for particleboard manufacturing. Besides wood, they can use residues from agribusiness such as: cereal straw, bagasse of sugar cane, cornstalks and corn cobs, cotton stalks, kenaf, rice husks, sunflower stalks and hulls, among others ${ }^{2}$. Within these, rice husk presents the highest potential for utilization. Rice is one of the most consumed cereals in the world. Only in Brazil, which is just the

*e-mail: rrmelo2@yahoo.com.br ninth largest producer in the world, a production of nearly 12 million tons of rice per crop (about $2 \%$ of the global production) is estimated, whereas most part is concentrated in its southern states. Considering that the husk accounts for nearly $20 \%$ of the grain weight, annually, it would be generated about 2.4 million tons of this residue by that country $^{3}$. Ndazi et al. ${ }^{4}$ mentioned that rice husk is one of the agricultural residues easily available in large amounts and, therefore, can be considered an excellent raw material for manufacturing particleboards. However, particleboards produced with this material have been presenting deficient gluing owing to the lack of direct interaction between this product and commercial adhesives. This behavior was also verified by Ajiwe et al. ${ }^{5}$ and Melo et al. ${ }^{3}$, while assessing particleboards manufactured with different proportions of wood and rice husk particles.

Apart from residues, the raw materials found in large amount at regional level can decrease the final cost of the product. This is the case of bamboo, which has been used at industrial scale in several Asian countries such as: China, India, Thailand, Vietnam and Malaysia ${ }^{6,7}$. In Brazil, in spite of genera (34) and species (232, whereas 174 are endemic) diversity, bamboo's potential has been poorly utilized ${ }^{8}$. Several studies have indicated that particleboards using bamboo as raw material present satisfactory performance with respect to physical-mechanical properties ${ }^{8-10}$.

Hiziroglu et al. ${ }^{11}$, while studying particleboards manufactured with different proportions of wood (Eucalyptus camaldulensis), rice straw and bamboo particles, observed for the particleboards made with wood-rice straw, rice 
straw-bamboo, and for the combination between them, inferior mechanical properties (internal bonding, modulus of elasticity and modulus of rupture) compared to those manufactured only with wood particles. These authors still verified, with respect to physical properties, lower dimensional stability for these particleboards. However, wood-bamboo particleboards obtained similar or better performance than those manufactured only with wood particles.

In the present study, it was assessed the physical and mechanical properties of particleboards manufactured with wood, rice husk and bamboo particles, in different combinations.

\section{Material and Methods}

\subsection{Raw material collection and preparation}

Particleboard manufacturing was carried out using eucalyptus wood $(\mathrm{W})$, rice husk $(\mathrm{R})$ and bamboo (B) particles. The wood particles (Eucalyptus grandis W. Hill ex Maiden) were obtained from six trees from homogeneous forest stands with nearly 15 years. The boards were obtained from the trees, which, were then resawed with perpendicularto-grain cut, obtaining blocks with 5-cm width (tangential), 7-cm length (longitudinal) and variable thickness (radial), according to the diameter and position of the board removal from the log. The blocks were transformed in flakes in a knife mill, and, then, in particles after being processed in a hammer mill with 8.0-mm diameter mesh sieve. Afterwards, fines were removed by a sieve with $1.0 \times 1.0 \mathrm{~mm}$ mesh.

The rice husks (Oryza Sativa L.) were obtained from a rice processing mill. First, the material was cleaned and selected. Then, the husks were processed in hammer mill using a sieve with $6.0-\mathrm{mm}$ mesh. Afterwards, the fines were removed by a sieve with $1.0 \times 1.0 \mathrm{~mm}$ mesh. Yet, the bamboo culms (Bambusa vulgaris Schr.) were obtained in clumps of nearly four years of age. They were cut at $2 \mathrm{~m}$ above ground level and, then, cut in longitudinal direction and immersed into water so as to increase its internal face exposition, to remove part of the starch and to facilitate its grinding process ${ }^{9}$. The culms were grinded by a hammer mill coupled with a 6.0-mm diameter mesh sieve. After drying in oven at $60^{\circ} \mathrm{C}$ temperature, this material was sieved in $1.0 \times 1.0 \mathrm{~mm}$ mesh, aiming at better selecting the material and removing the fines.

\subsection{Particleboards manufacturing}

The wood, rice husks and bamboo particles selected were conditioned in oven at $60^{\circ} \mathrm{C}$ during 24 hours, where they reached equilibrium moisture content of nearly $3 \%$. They were used separately or combined in different proportions (Table 1). In all cases, it was used the ureaformaldehyde adhesive $(350 \mathrm{cP}$ viscosity and $65 \%$ content of solids) in the proportion of $8 \%$ of the particles dry mass. It was still added $1 \%$ of paraffin in the same conditions. The particle mass of the particleboards (pure or combined) was represented by $91 \%$ of the manufactured particleboard mass loss. The adhesive and the paraffin were added to the particles mass through a pistol triggered by air compressor in a rotating roller.
Table 1. Proportion of particle type for each treatment.

\begin{tabular}{cccc}
\hline \multirow{2}{*}{ Treatment } & \multicolumn{3}{c}{ Proportion } \\
\cline { 2 - 4 } & Wood & Bamboo & Rice husk \\
\hline W & 100 & - & - \\
B & - & 100 & - \\
R & - & - & 100 \\
WB & 50 & 50 & - \\
WR & - & 50 & 50 \\
\hline
\end{tabular}

$\mathrm{W}=$ wood particles; $\mathrm{B}=$ bamboo particles; $\mathrm{R}=$ rice husk particles.

Afterwards, the mass of particles with adhesive and paraffin was taken to a wooden mould with $50 \mathrm{~cm} \times 50 \mathrm{~cm} \times 20 \mathrm{~cm}$, where it was manually pressed. Then, the definitive pressing was carried out in hydraulic press, at $180^{\circ} \mathrm{C}$ temperature and $3.0 \mathrm{~N} / \mathrm{mm}^{2}$ pressure. The shutdown period of the press was 40 seconds, and 8 minutes was the total pressing period necessary to promote water evaporation and adhesive solidification. Overall, 30 particleboards were produced (six per treatment), all with pre-established nominal specific mass of $0.65 \mathrm{~g} / \mathrm{cm}^{3}$ and dimensions of $50 \mathrm{~cm} \times 50 \mathrm{~cm} \times 0.95 \mathrm{~cm}$.

\subsection{Assays performed and analyses of the results}

In order to evaluate the properties of the particleboards produced, physical (density; moisture content; water absorption and thickness swelling) and mechanical (static bending; internal bonding and screw withdrawal) assays were carried, according to the American Society for Testing and Materials - ASTM D $1037^{12}$ standard. The average values observed for the physical-mechanical properties were compared with the minimum required by the norm of the American National Standards Institute - ANSI 208. $1^{13}$. For all cases, the data obtained was assessed through analysis of variance with further comparison of means by Student's $\mathrm{T}$ test $(\mathrm{p}<0.05)$.

\section{Results and Discussion}

\subsection{Physical properties}

The data obtained for specific mass and equilibrium moisture content of the particleboards for the different treatments evaluated did not differ statistically. In respect of specific mass, the mean values obtained for the treatments varied from $0.63 \mathrm{~g} / \mathrm{cm}^{3}$ to $0.69 \mathrm{~g} / \mathrm{cm}^{3}$. Moisture content verified varied from $8.29 \%$ to $8.75 \%$. This low variation enables greater reliability with regard to the other results obtained, as moisture and specific mass, especially, influence significantly the physical-mechanical properties of the particleboards ${ }^{14}$.

With respect to water absorption, it was observed that after the 2-hour and 24-hour period post-immersion, particleboards manufactured exclusively with alternative particles ( $\mathrm{B}$ and $\mathrm{R}$ ) or through their mixture with wood particles (WB and WR) showed increase in percentages of water absorption (Figure 1). Similar results were observed by Melo et al. ${ }^{3}$ and Calegari et al. ${ }^{9}$. According to these 
authors the highest percentages of water absorption for these particleboards can be related to the high content of silica (R) and to the lower content of lignin (B) present in these materials. Such components interfere with the particles' adhesion and gluing processes, such as silica, or with the increase on the proportion of celluloses and polyoses chemical constituents with hydrophilic behavior, such as lignin.

Regarding thickness swelling (Figure 2), the highest instability was verified for particleboards that only used rice husk $(\mathrm{R})$, or for those wherein these were mixed with wood (WR). The particleboards which used bamboo (B and WB) presented loss of early stability, i.e. higher thickness swelling - after 2-hour immersion; however, when the swelling of the samples after 24 hours is considered, these particleboards showed similar performance compared to those only with wood particles (W). The percentages of thickness swelling observed for W, B and WB particleboards fulfilled the ANSI 208. $1^{13}$ requirements for commercialization, which accepts absorption percentages of up to $35 \%$ at 24-hour after immersion. The good performance of particleboards manufactured with bamboo, with respect to its dimensional stability, was also observed by Hiziroglu et al. ${ }^{11}$. The same authors also evinced that particleboards produced with rice straw showed high water absorption and thickness swelling, which significantly reduced when the particleboards were mixed with wood in the same proportion.

\subsection{Mechanical properties}

The use of $\mathrm{R}$ particles indicated a reduction in rigidity $\left(E_{M}\right)$ and resistance $\left(f_{M}\right)$ to static bending (Figure 3). Other researchers, such as Ajiwe et al. ${ }^{5}$, Han et al. ${ }^{15}$, Lee and $\mathrm{Kang}^{16}$, Ndazi et al. ${ }^{4}$ and Melo et al. ${ }^{3}$, also obtained similar results, wherein the rise in the proportion of rice husk in particleboards caused a decrease in resistance and rigidity parameters of these materials. Similarly, the use of rice straw for panel manufacturing, as verified by Hiziroglu et al. ${ }^{11}$, also presented results similar to this study.

With respect to the particleboards which used B particles, even though they have presented lower $E_{M}$ and $f_{M}$ than the particleboards which exclusively used $\mathrm{W}$ particles, their influence on the performance of the particleboards was less damaging than those using R particles. Regarding $E M$, it was observed statistically similar results between $\mathrm{W}$ and WB particleboards. The good performance of bamboo particles in particleboards was also observed by Lee et al. ${ }^{17,18}$, $\mathrm{Xu}$ et al. ${ }^{19}$, Hiziroglu et al. ${ }^{11}$ and Calegari et al. ${ }^{9}$. The minimum values standardized by ANSI A 208.1 ${ }^{13}$ for medium density particleboards $\left(0.60 \mathrm{~g} / \mathrm{cm}^{3}\right.$ to $\left.0.85 \mathrm{~g} / \mathrm{cm}^{3}\right)$

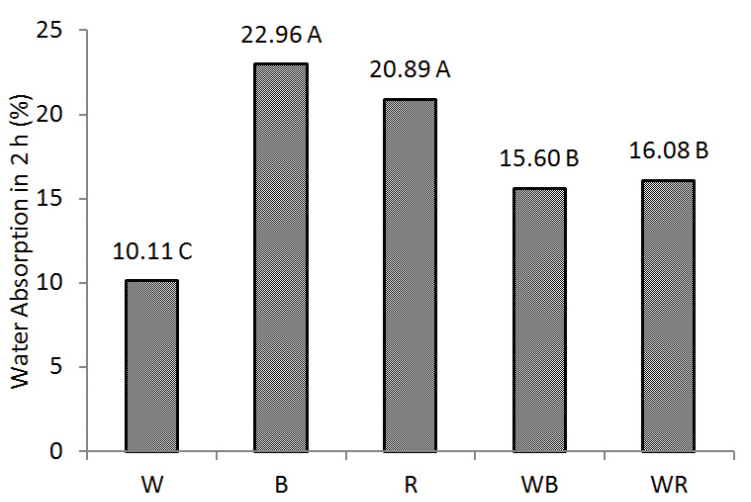

(a)

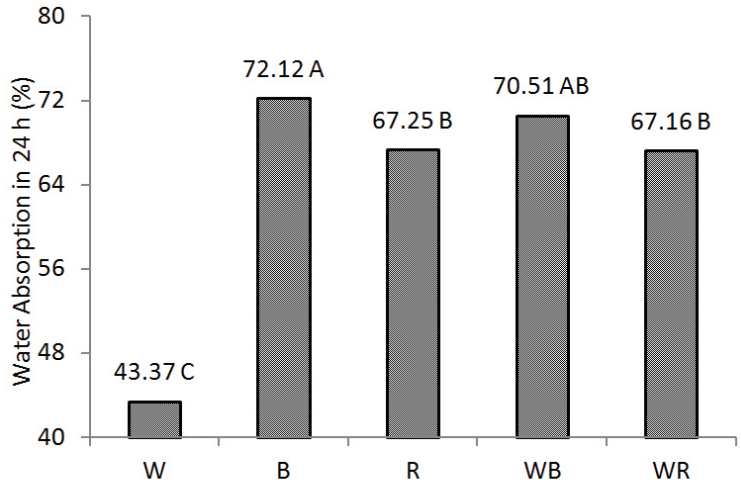

(b)

Figure 1. Water absorption in 2 and 24 hours of the panels. $\mathrm{W}=$ wood particles; $\mathrm{B}=$ bamboo particles; $\mathrm{R}=$ rice husk particles.

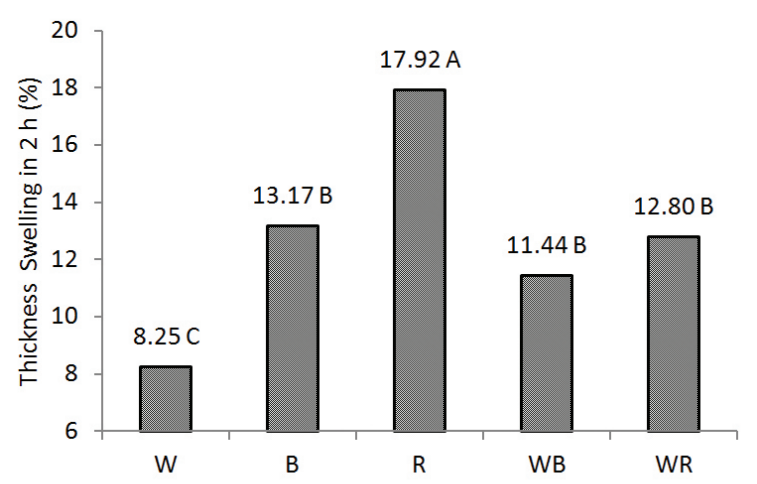

(a)

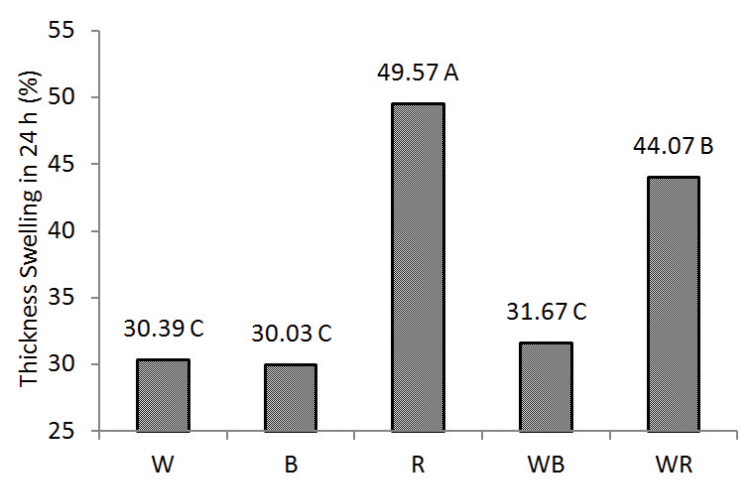

(b)

Figure 2. Thickness swelling in 2 and 24 hours of the panels. $\mathrm{W}=$ wood particles; $\mathrm{B}=$ bamboo particles; $\mathrm{R}=$ rice husk particles. 


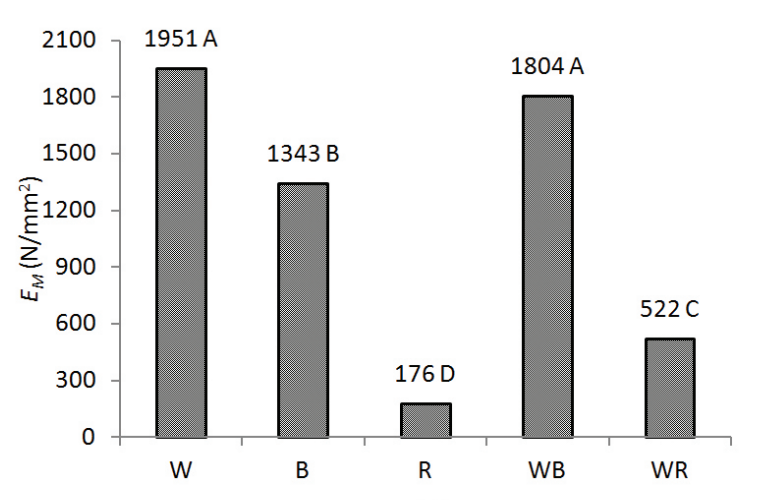

(a)

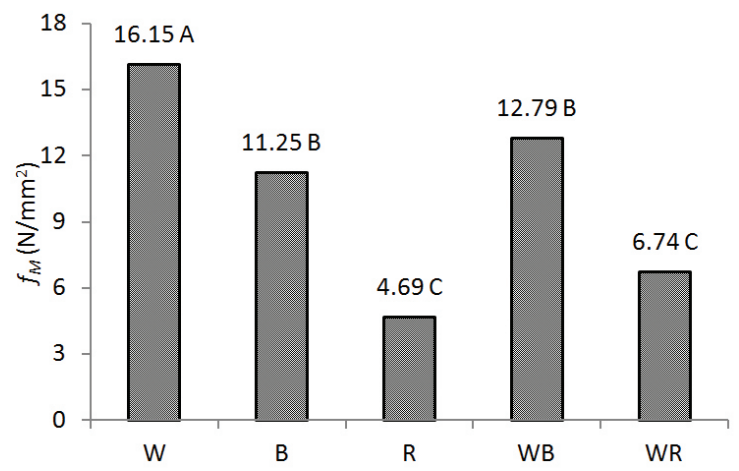

(b)

Figure 3. Results of the static bending tests. $\mathrm{W}=$ wood particles; $\mathrm{B}=$ bamboo particles; $\mathrm{R}=$ rice husk particles.

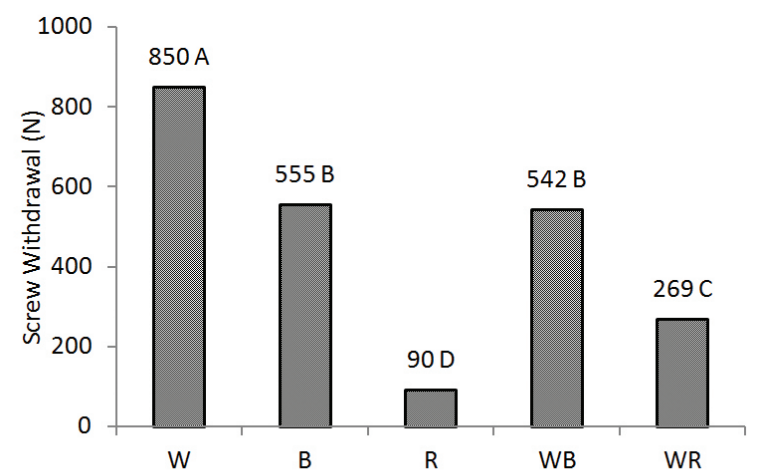

(a)

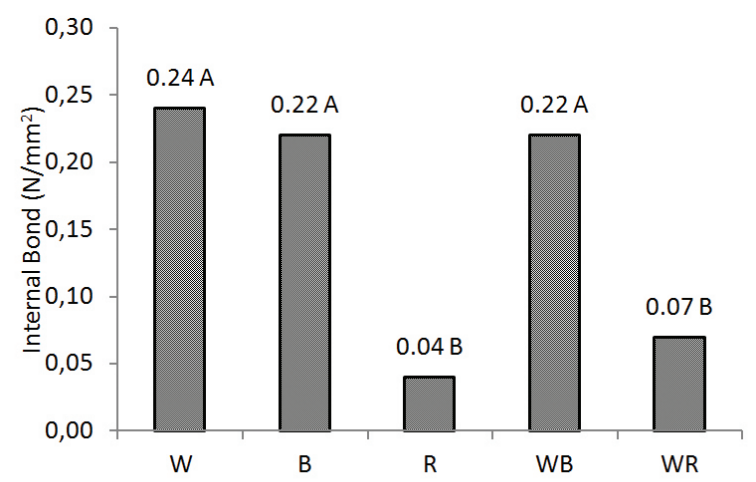

(b)

Figure 4. Results of the screw withdrawal and internal bond tests. $\mathrm{W}=$ wood particles; $\mathrm{B}=$ bamboo particles; $\mathrm{R}=$ rice husk particles.

are $1760 \mathrm{~N} / \mathrm{mm}^{2}$ for $E_{M}$ and $11 \mathrm{~N} / \mathrm{mm}^{2}$ for $f_{M}$, which were reached by the $\mathrm{W}$ and $\mathrm{WB}$ particleboards.

The assessed particleboards presented significant difference when resistance to screw withdrawal was evaluated (Figure 4). The highest resistance was observed for samples using $\mathrm{W}$ particles, followed by those with $\mathrm{B}$ and WB particles. The lowest resistance to screw withdrawal was observed for particleboards produced with $\mathrm{R}$ and WR particles. Similar results were found by Calegari et al. ${ }^{9}$ for bamboo-wood particleboards and by Melo et al. ${ }^{3}$ for woodrice husk particleboards.

Within the properties evaluated in the present work, internal bonding is one of the most important for the qualitative characterization of the particleboards. This parameter indicates how significant was the interaction performed between the particles and the adhesive used, and is directly related to all the other physical-mechanical properties evaluated in this study. Particleboards produced with $\mathrm{W}, \mathrm{B}$ and $\mathrm{WB}$ particles presented similar values of resistance to bonding. The potential of bamboo use for particleboard manufacturing was also pointed by several studies $^{8-11,20}$. Yet, for particleboards manufactured with $\mathrm{R}$ and WR particles, the internal bonding was substantially affected. The low values of internal bonding may be related to the cylindrical and hollow structure of the rice husk particles, which may have acted as a barrier during resin application ${ }^{3}$. Another probable influence is the low permeability mentioned by Youngquist et al. ${ }^{2}$, which may have interfered on the particles' gluing. Lee and $\mathrm{Kang}^{16}$ also observed that the use of rice husk particles in particleboards promoted great reduction in their physical and mechanical resistance properties. However, its increase in small concentrations, up to $10 \%$, likewise observed by Melo et al. ${ }^{3}$, may not present any significant impact on the particleboards' properties.

The minimum values required by ANSI A 208.1 13 standard for resistance to screw withdrawal and internal bonding for the types of particleboards studied are nearly $1,000 \mathrm{~N}$ and $0.40 \mathrm{~N} / \mathrm{mm}^{2}$, respectively. None of the treatments evaluated managed to fulfill the requirements established by these parameters.

\section{Conclusions}

The use of bamboo particles was proved as promising for the production of particleboards, not only for those made exclusively with bamboo particles, but also through the combination with wood particles. In certain cases, it was observed similar results obtained by these compared to particleboards manufactured exclusively with wood particles. The bamboo particles has potential for this purpose, with the 
possibility of adjustment of some production parameters for reaching performance equivalent to wood panel.

Rice husk particles presented restrictions for utilization in particleboard manufacturing, once their use, isolated or combined with wood particles, provided major reduction in the physical-mechanical properties of the particleboards.

\section{References}

1. Fiorelli J, Sertori DL, Cravo JCM, Savastano H Jr, Rossignolo JA, Nascimento MF et al. Sugarcane bagasse and castor oil polyurethane adhesive-based particulate composite. Material Research. 2013; 16:439-446. http://dx.doi.org/10.1590/S151614392013005000004

2. Youngquist JA, Krzysik AM, English EW, Spelter HN and Chow P. Agricultural fibers in composition panels. In: Proceedingsof the 27th International Particleboard/ Composite Materials Symposium; 1996; Pullman. Washington: Washington State University; 1996. p. 133-152.

3. Melo RR, Santini EJ, Haselein CR and Stangerlin DM. Propriedades físico-mecânicas de painéis aglomerados produzidos com diferentes proporções de madeira e casca de arroz. Ciência Florestal. 2009; 19(4):449-460.

4. Ndazi B, Tesha JV, Karlsson S and Bisanda ETN. Production of rice husks composites with Acacia mimosa tannin-based resin. Journal of Material Science. 2006; 41(21):6978-6983. http://dx.doi.org/10.1007/s10853-006-0220-7

5. Ajiwe VIE, Okeke CA, Ekwuozor SC and Uba IC. A pilot plant for production of ceiling boards from rice husks. Bioresource Technology. 1998; 66(1):41-43. http://dx.doi.org/10.1016/ S0960-8524(98)00023-6

6. Kasim J, Ahmad AJH, Harun J, Ashari Z, Mohmod L and Yusof MNM. Properties of particleboard manufactured from commonly utilized Malaysian bamboo (Gigantochloa scortechinii). Pertanika Journal Tropical Agricultural Science. 2001; 24(2):151-157.

7. Lin CJ, Tsai MJ and Wang SY. Nondestructive evaluation techniques for assessing dynamic modulus of elasticity of moso bamboo (Phyllostachys edulis) lamina. Journal of Wood Science. 2006; 52(4):342-347. http://dx.doi.org/10.1007/ s10086-005-0772-1

8. Arruda LM, Del Menezzi CHS, Teixeira DE and Araújo PC. Lignocellulosic composites from Brazilian giant bamboo (Guadua magna). Part 1: properties of resin bonded particleboards. Maderas: Ciencia y Tecnología. 2011; 13(1):4958. http://dx.doi.org/10.4067/S0718-221X2011000100005

9. Calegari L, Haselein CR, Scaravelli TL, Santini EJ, Stangerlin DM, Gatto DA et al. Desempenho físico-mecânico de
Nevertheless, its use in small concentrations and/or with application of other types of adhesives needs to be thoroughly studied.

The values standardized by ANSI A 208.113 for medium density particleboards which were reached by the wood and wood-bamboo panels.

painéis fabricados com bambu (Bambusa vulgaris Schr.) em combinação com madeira. Cerne. 2007; 13(1):57-63.

10. Araújo PC, Arruda LM, Del Menezzi CHS, Teixeira DE and Souza MR. Lignocellulosic composites from Brazilian giant bamboo (Guadua magna). Part 2: Properties of cement or gypsium-bonded particleboard. Maderas: Ciencia y Tecnología. 2011; 13(3):297-306. http://dx.doi.org/10.4067/ S0718-221X2011000300005

11. Hiziroglu S, Jarusombuti S and Fueangvivat V. Properties of bamboo-rice straw-eucalyptus composite panels. Forest Products Journal. 2005; 55(12):221-225.

12. American Society for Testing and Materials-ASTM. Standard test methods for evaluating properties of wood-base fiber and particle panel materials: specification ASTM D 1037-98. Philadelphia: ASTM; 1998

13. American National Standard Institute - ANSI. Mat-formed wood particleboard: specification ANSI A 208.1.1993. Gaithersburg: National Particleboards Association; 1993.

14. Melo RR and Del Menezzi CHS. Influência da massa específica nas propriedades físico-mecânicas de painéis aglomerados. Silva Lusitana. 2010; 18(1):59-73.

15. Han G, Zhang C, Zhang D, Umemura K and Kawai S. Upgrading of urea formaldehyde-bonded reed and whet straw particleboards using silane coupling agents. Journal of Wood Science. 1998; 44(4):282-286. http://dx.doi.org/10.1007/ BF00581308

16. Lee HH and Kang CW. Development of rice hull insulation board using urea formaldehyde resin. Journal of Korean Wood Science and Technology. 1998; 26(4):50-55.

17. Lee AWC, Bai X and Bangi AP. Flexural properties of bamboo-reinforced southern pine OSB beams. Forest Products Journal. 1997; 47(6):74-78.

18. Lee AWC, Bai X and Peralta PN. Physical and mechanical properties of strandboard made from Moso bamboo. Forest Products Journal. 1996; 46(11-12):84-88.

19. Xu H, Tanaka C, Nakao $T$ and Katayama H. Mechanical properties of plywood reinforced by bamboo or jute. Forest Products Journal. 1998; 48(1):81-85.

20. Vital BR and Haselein CR. Qualidade de chapas de aglomerado produzidas com embaúba (Cecropia sp.) e bambu (Bambusa vulgaris). Revista Árvore. 1988; 12(2):134-145. 